Barriers to gene flow

\section{R. K. Butlin}

Species Evolution: The Role of Chromosome Change. By Max King. Cambridge University Press: 1993. Pp. 336. £40, $\$ 59.95$.

FIFTEEN years ago Michael White published Modes of Speciation, in which he argued that chromosomal change plays an important part in the origin of species. Max King believes that the book, a masterful synthesis of data in support of this position, has received far less attention than it deserves and that the role of chromosomal change has been played down consistently by the "essentially North American coterie of like-minded geneticists" who, from his Australian perspective, currently dominate the field. $\mathrm{He}$ sets out on a crusade to reinstate cytogenetics (or cytogeneticists?) in its rightful place and to show what progress has been made since 1978 despite the perceived neglect.

All models of speciation need to overcome the same central problem: a mutant allele that contributes to reproductive isolation must be at a selective disadvantage when it first appears in a population. Non-chromosomal models have various ways around this obstacle, but chromosomal theories generally tackle it head on. The case for a primary role of chromosomes in speciation is based on the strong fitness reduction in heterozygotes produced by some types of rearrangement that generate, in one step, a substantial barrier to gene flow. King offers a familiar pair of circumstances to overcome the problem of the spread of such a rearrangement: inbreeding in small populations and meiotic drive. It is not clear why these conditions should apply to chromosomal rearrangements and not to single-locus mutations with large effects on the fitness of heterozygotes. Although King argues that the chromosomal mutation rate is high (greater than 1 in 500 ), this is not high relative to the per-genome rate for single-locus mutations. His claim that meiotic drive is an important evolutionary force may be much less controversial now than in 1978 , but the link between meiotic drive and underdominant chromosomal rearrangements remains tenuous.

Few would doubt the evidence, which King presents at length, that some chromosomal rearrangements contribute to selection against interspecific hybrids. The question is whether the chromosomal change is the primary event in the speciation process. Here, King relies on evidence from allozymes to measure 'genic' divergence and marshals examples in which chromosomal changes characterize taxa that lack 'genic' differentiation. The example of the alpine grasshopper, Podisma pedestris, clearly shows the danger of this argument. There is strong evidence that many genes contribute to postzygotic isolation between races despite the absence of allozymic differentiation, but the overall isolation is much greater than the isolation produced by the chromosomal fusion that characterizes them. It seems likely that the main difference between chromosomal and genic contributions to reproductive isolation is simply that chromosomal changes can be seen under a microscope: either can evolve without allozymic divergence.

In his final comments, King laments "a failure to integrate specific findings into a common evolutionary perspective". Sadly, this is precisely the problem with his book: he makes a case, and makes it well, for the existence of chromosomal speciation but he does not provide arguments for its importance relative to other modes of speciation. Like its predecessor, the book deserves a readership among workers in the field, but for a general coverage of 'species evolution' one will have to look elsewhere.

R. K. Butlin is in the Department of Genetics, University of Leeds, Leeds LS2 9JT, UK.

\section{Star wars}

\section{JoelA. Gwinn}

Pauper and Prince: Ritchey, Hale, and Big American Telescopes. By Donald E. Osterbrock. University of Arizona Press: 1993. Pp. 359. $\$ 45$.

THE giant telescopes constructed during the first half of the twentieth century have revealed much about our place in the cosmos. We now know a great deal about the astrophysics of the Sun and its system of planets and the relative position of our Solar System in the Milky Way; and spectral classification of stars has led to new methods of determining stellar distances and, through establishment of intergalactic distances, to the modern cosmological view of a Universe expanding from an initial Big Bang.

The 1888 dedication of Lick Observatory, with its 36-inch refracting telescope, marked the beginning of a trend of building huge telescopes for astronomical research. The wealthy individuals and foundations able to provide the requisite funds were typically motivated by a desire to build "the world's largest telescope". In the astronomical community, George

\section{IMAGE UNAVAILABLE FOR COPYRIGHT REASONS}

Hale: nobility of wealth.

Ellery Hale is well known for his success in identifying potential donors and persuading them to support the next venture.

Hale was also an accomplished research astronomer in his own right. While Hale was still a student at the Massachusetts Institute of Technology, his father provided for him, on a lot next to the family home, his own fully equipped observatory, the Kenwood Physical Laboratory. Over the years, this wealthy Chicago businessman provided telescopes and observatories, and hired assistants to further his son's career in astronomy. American nobility is a nobility of wealth, and George Ellery Hale was a true member of this nobility, with all the status and privileges that come with it, together with the neurosis and arrogance, as we find out in this remarkable book.

As a newly appointed associate professor of astrophysics at the University of Chicago, Hale obtained two 40-inch glass disks, and, together with W. R. Harper, the president of the university, persuaded Charles T. Yerkes, the Chicago street-car magnate, to pay for a new observatory based on a new refracting telescope even larger than the 36-inch giant at Lick Observatory.

Born almost five years before Hale, George Willis Ritchey was a descendant of Scotch-Irish immigrant craftsmen. He was not entitled to the rights and privileges of American nobility of wealth. All his life, he lacked the money needed to pursue his creative visions, prohibitively expensive owing to his standards of perfection.

Working as an optician on a salary provided by Hale's father, Ritchey developed a symbiotic relationship with Hale, first at Kenwood, and then at Yerkes, where he obtained better photo- 